\title{
Numerical Simulation of the Early Age Three-Dimensional Microstructure Development of Cement Pastes
}

\author{
Yunsheng Zhang, Zhiyong Liu, and Wei Sun \\ Jiangsu Key Laboratory for Construction Materials, Southeast University \\ Zhiyong Liu \\ Jiangsu Key Laboratory of Environmental Impact and Structural Safety in Engineering, \\ China University of Mining and Technology
}

\begin{abstract}
The formation process of microstructure in cement pastes was first simulated with a numerical model CEMHYD3D. The influence of water-to-cement ratio and particles size on heat release and degree of hydration were then investigated. In addition, the mass of $\mathrm{CH}$ and $\mathrm{C}-\mathrm{S}-\mathrm{H}$ phases simulated have been verified by measuring values by thermogravimetry-differential scanning calorimetry (TG-DSC) and X-ray diffraction (XRD)-Rietveld analysis. The evolutions of solids phase percolation and capillary pores de-percolation were also identified by means of a three-dimensional (3D) numerical model. The results show that the simulated values are in good agreement with the available experimental data, indicating a good reliability of the CEMHYD3D model.
\end{abstract}

Keywords: cement paste, microstructure, numerical model.

\section{INTRODUCTION}

The microstructure of cement-based materials determines the macro performances, including mechanical and service life properties. Various experimental tests, such as Vicat needle and penetration resistance methods (Ylmen, Jaglid, Steenari, \& Panas, 2009), scanning electron microscopy (SEM) (Venkiteela \& Sun, 2010), X-ray diffraction (XRD) (Scrivener, Fullmann, Gallucci, Walenta, \& Bermejo, 2004), ultrasonic pulse velocity (Liu, Zhang, Jiang, Sun, \& Zhang, 2011; Zhang, Zhang, She, Ma, \& Zhu, 2012), and electrical resistivity (Liu, Zhang, Sun, \& Jiang, 2012; Xiao \& Li, 2009) are applied to investigate the microstructure parameters. However, these experimental methods are not only time consuming and destructive but also only partly provide information.

Similar to the realistic microstructure, the numerical model is a good way to simulate the change of three-dimensional (3D) microstructures of cementbased materials. In this study, the 3D microstructure is simulated using a digital image hydration model CEMHYD3D. In addition, simulated results of main hydration products are compared with results obtained by XRD-Rietveld and thermal gravimetric analysis at various times of hydration.

\section{NUMERICAL MODELING}

The microstructure of cement paste is conducted using CEMHYD3D developed by Bentz $(2006,2005)$. In this digitized model, the initial 3D microstructure is first built on basis of real W/C, particle size distribution of cement, chemical composition, and spatial distribution of mineral phases. Hydration process was then executed by applying a cellular-automata algorithm for a series of dissolution, discussion, and reaction cycles. Finally, the microstructure information, including a volume of solid phases and capillary pores, as well as hydration heat and degree, can be achieved at any hydrated time. Moreover, the percolation process of capillary pores and solid phases are easily evaluated by the application of a "burning algorithm".

\section{MATERIALS AND METHODS}

\subsection{Materials}

A Chinese standard Graded 52.5 P I type Portland cement with the compressive strength and flexure strength of 60.5 and $8.7 \mathrm{MPa}$ respectively, at 28 days, similar to ASTM C150 type I cement, was used in this study. This cement was also tested by X-ray fluorescence spectrometer (JY/T 016-1996) and its chemical compositions and physical properties are listed in Table 1. Additionally, the particle size distribution of cement, measured by LPSA (Microtrac S3500), is provided in Figure 1.

\subsection{Experimental methods}

The samples of cement paste were crushed and ground into powder with $<0.08 \mathrm{~mm}$. Thermogravimetry-differential scanning calorimetry 
Table 1. Chemical compositions and physical properties of Portland cement.

\begin{tabular}{|c|c|c|c|c|c|c|c|c|c|}
\hline \multicolumn{8}{|c|}{ Chemical composition (\%) } & \multirow[b]{2}{*}{$\begin{array}{l}\text { Specific surface } \\
\text { area }\left(\mathrm{m}^{2} / \mathrm{kg}\right)\end{array}$} & \multirow[b]{2}{*}{ Density $\left(\mathrm{kg} / \mathrm{m}^{3}\right)$} \\
\hline $\mathrm{SiO}_{2}$ & $\mathrm{Al}_{2} \mathrm{O}_{3}$ & $\mathrm{Fe}_{2} \mathrm{O}_{3}$ & $\mathrm{CaO}$ & $\mathrm{MgO}$ & $\mathrm{SO}_{3}$ & $\begin{array}{l}\text { Other } \\
\text { oxides }\end{array}$ & $\begin{array}{l}\text { Loss on } \\
\text { ignition }\end{array}$ & & \\
\hline 21.35 & 4.67 & 3.31 & 62.6 & 3.08 & 2.25 & 1.79 & 0.95 & 369.6 & 3150 \\
\hline
\end{tabular}

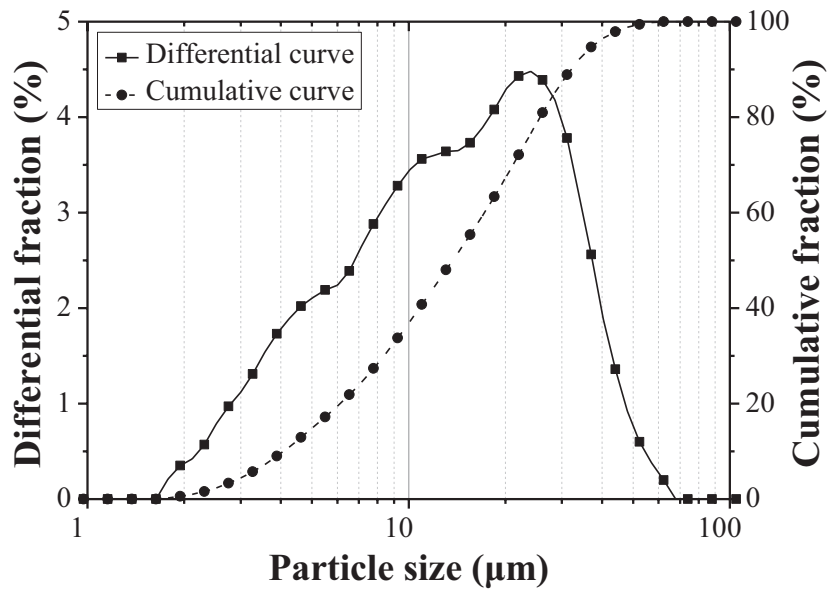

Figure 1. Measured particle size distribution for cement.

(TG-DSC) were used to calculate the percentage of $\mathrm{CH}$. Scanning was done from room temperature to $1200^{\circ} \mathrm{C}$ with a $10^{\circ} \mathrm{C} / \mathrm{min}$ heating rate. The amorphous $\mathrm{C}-\mathrm{S}-\mathrm{H}$ phase was quantified by XRD-Rietveld method. The samples measured by XRD were prepared by mixing 10 mass $\%$ corundum server as an internal standard. The software of TOPAS was used for Rietveld analysis.

\section{RESULTS AND DISCUSSION}

\subsection{Simulated results}

The 3D images of a hydrated microstructure using CEMHYD3D simulation at different cycles (time) of hydration are shown in Figure 2. With development of hydration time, the volume fraction of mineral phases decreases and the hydrated products increase.

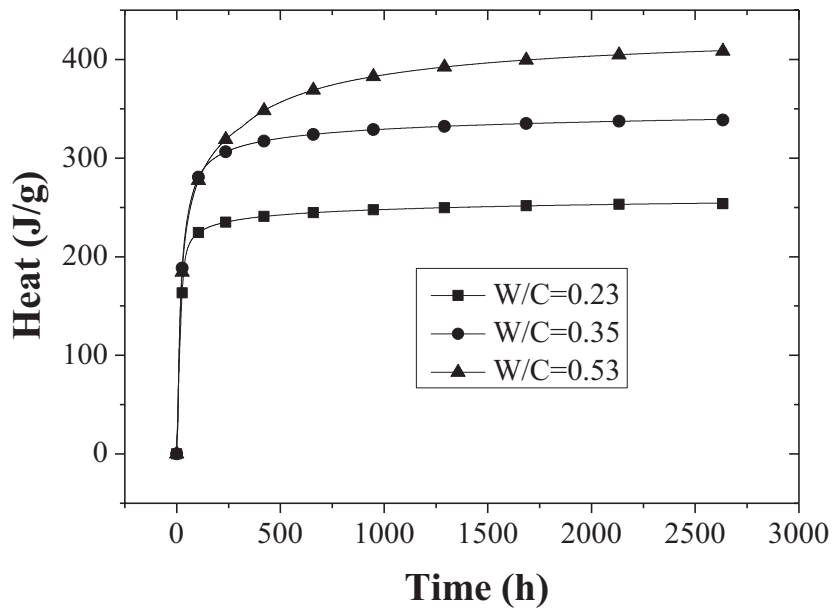

Figure 3. Influence of simulated W/C on heat release.

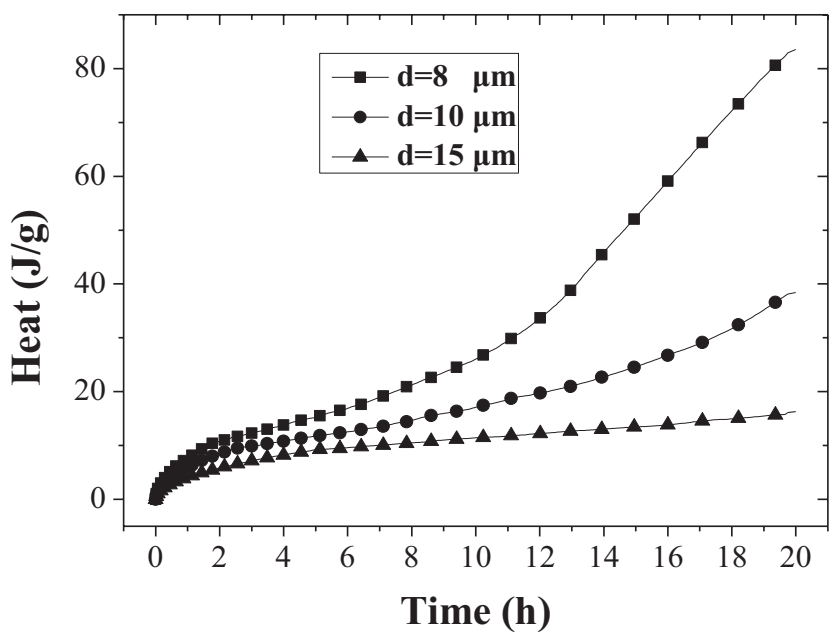

Figure 4. Influence of simulated particles size on heat release.

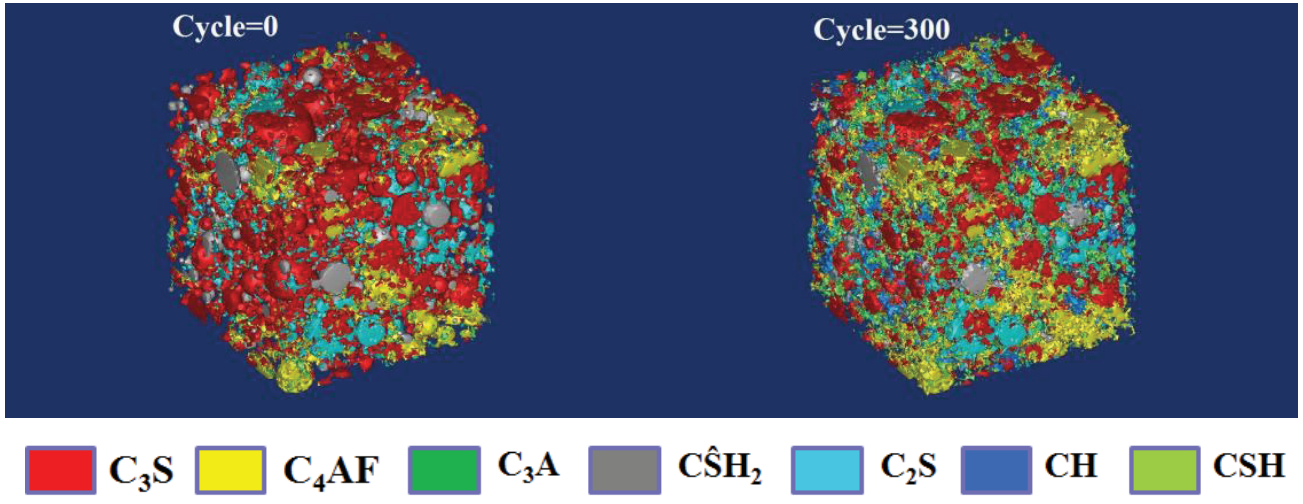

Figure 2. Simulation of hydrated $3 \mathrm{D}$ microstructure with W/C of 0.35 from 0 to 300 cycles (Red- $\mathrm{C}_{3} \mathrm{~S}$, skyblue- $\mathrm{C}_{2} \mathrm{~S}$, yellow- $\mathrm{C}_{4} \mathrm{AF}, \mathrm{green}-\mathrm{C}_{3} \mathrm{~A}$, gray-gypsum, blue- $\mathrm{CH}$, acqu-CSH). 
The influence of W/C and particle size on hydrated heat is shown in Figures 3 and 4, respectively. The heat release rapidly increases when cement particles come in contact with water. After that, the heat curve levels off at later ages. At $2500 \mathrm{~h}$, the heat release is increased by $61 \%$ for the paste with W/C of 0.53 than the one with W/C of 0.23 (Figure 3). This can be attributed to the fact that more water reacts with cement in the cement paste with high W/C. For the same W/C, the smaller particles show bigger heat release (Figure 4). Because of small cement particles with high specific surface area, more water comes in contact with particles that lead to high heat release of hydration. Similar to hydration heat, the hydration degree of cement pastes increase with the increase of W/C (Figure 5).

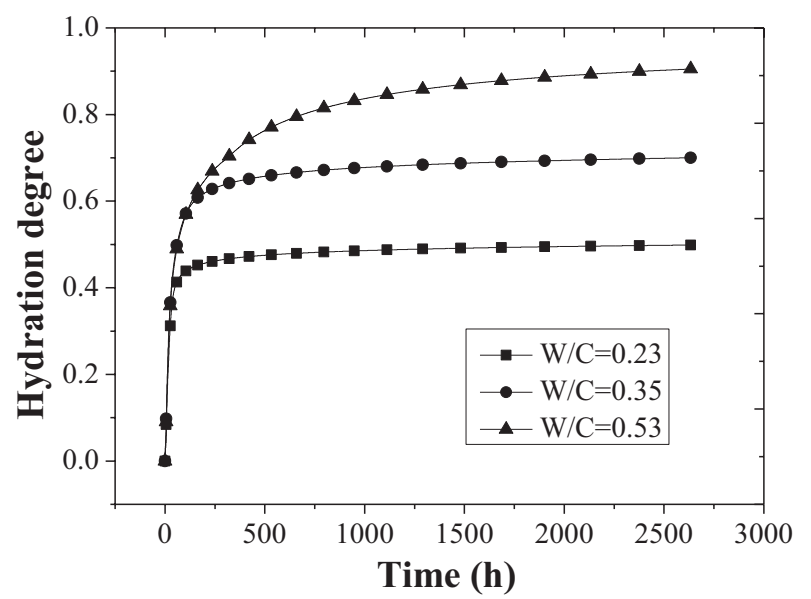

Figure 5. Influence of simulated W/C on hydration degree.

\subsection{Experimental verification}

The typical curve of TG-DSC is shown in Figure 6. An exothermic peak of DSC curve appears in the range of $400-450^{\circ}$ that corresponds to a region of significant mass decrease in the TG curve. Calcium hydroxide is decomposed into calcium oxide and water in this region. Therefore, the mass of $\mathrm{CH}$ is calculated according to Figure 6. Comparison $\mathrm{CH}$ of TG-DSC results and simulated values is presented in Figure 7. It is noted that experimental results are bigger than the simulated values and the maximum relative error is $36.76 \%$. This phenomenon can be explained by the fact that a decrease in mass is not only the decomposition of calcium hydroxide but also includes decomposition of other phases.

To validate the accuracy of the CEMHYD3D model, the mass fraction of $\mathrm{C}-\mathrm{S}-\mathrm{H}$ tested by XRD-Rietveld analysis is compared to simulated results, as shown in Figure 8. The maximum relative error is $32.9 \%$. In XRD-Rietveld analysis, the other amorphous phases of cement paste are also considered as $\mathrm{C}-\mathrm{S}-\mathrm{H}$ phase that result in overestimating the amount of $\mathrm{C}-\mathrm{S}-\mathrm{H}$.

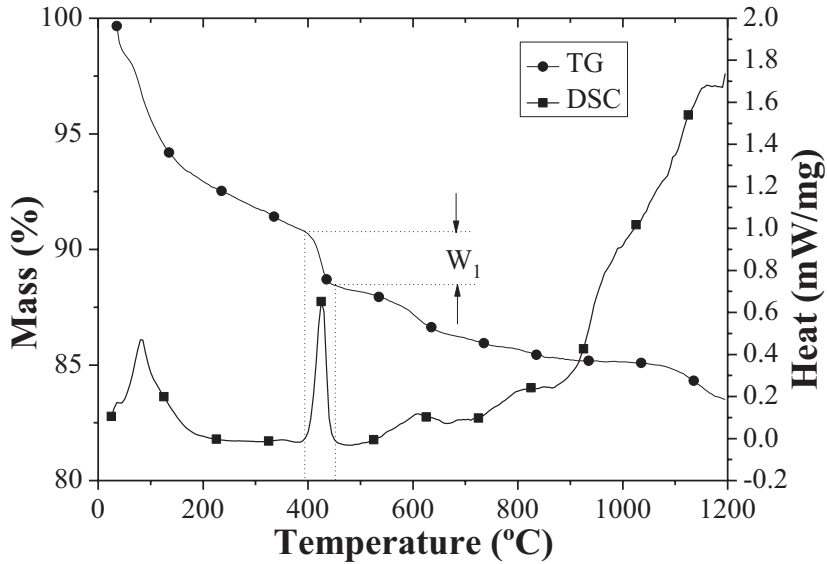

Figure 6. Typical curves of TG-DSC for cement paste $(\mathrm{W} / \mathrm{C}=0.23$, 1 day).

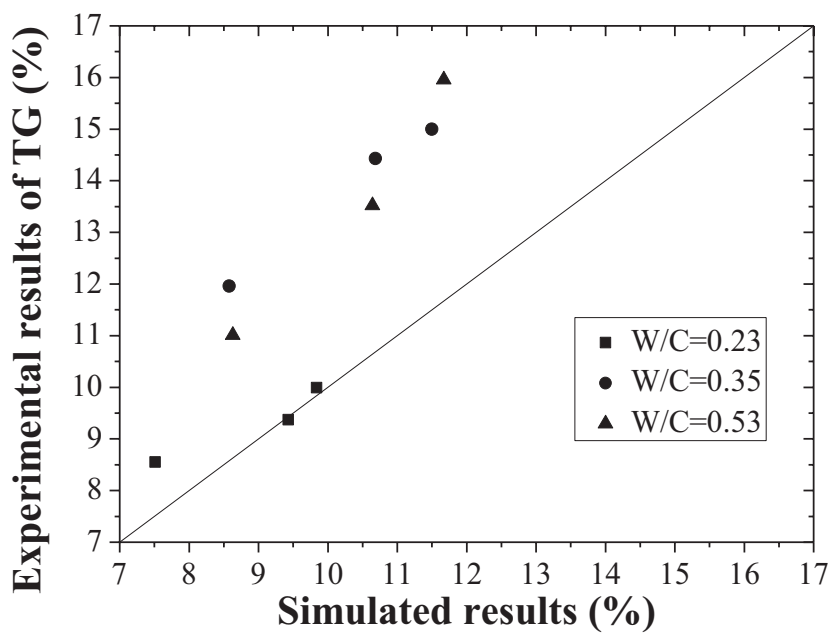

Figure 7. Comparison $\mathrm{CH}$ of TG-DSC results and simulated values.

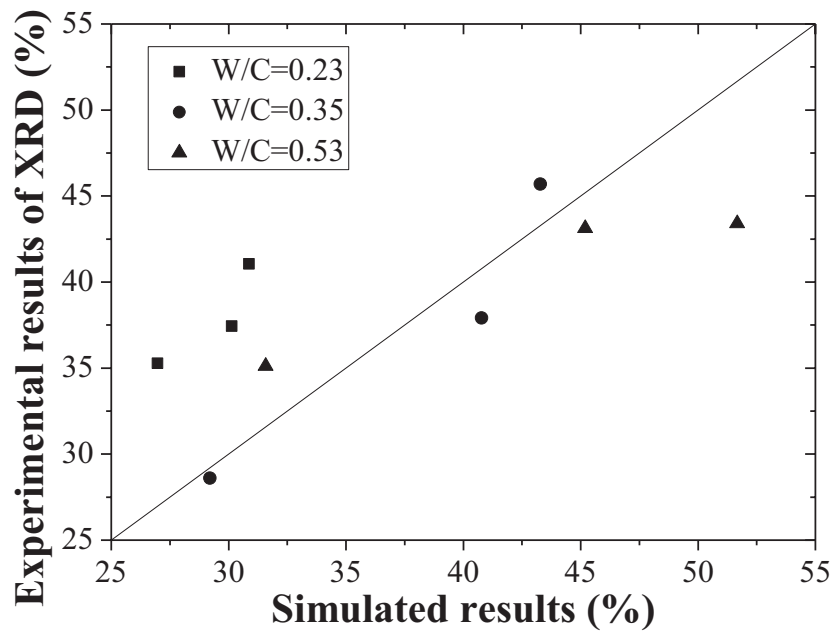

Figure 8. Comparison C-S-H of XRD-Rietveld results and simulated values. 


\subsection{Application of numerical model}

\subsubsection{Solid phases percolation}

Figure 9 shows the continuous development of solid phases modeled by CEMHYD3D for the values of W/C varying between 0.23 and 0.53 . After mixing fresh pastes, connected solid phases fraction equals 0 , indicating discontinuity of solid phases. When first percolation time arrives, the fraction of connected solid phases abruptly rises and gradually approximates to 1. It is clear from Figure 9 (a) that higher W/C results in longer first percolation time and full connection of solid phases. Because of higherW/C, the larger initial cement particles space leads to a looser microstructure. More hydration time is needed to form the bridges built by hydration products. In addition, for W/C of $0.23,0.35$, and 0.53 pastes, the percolation thresholds begin to appear when the volumetric fraction of total solids is $0.54,0.46$, and 0.36 , respectively [Figure $9(\mathrm{~b})$ ]. This implies that a low W/C requires more solids volume fraction to form a continuous solids path percolating the 3D microstructure. Similar results with an earlier
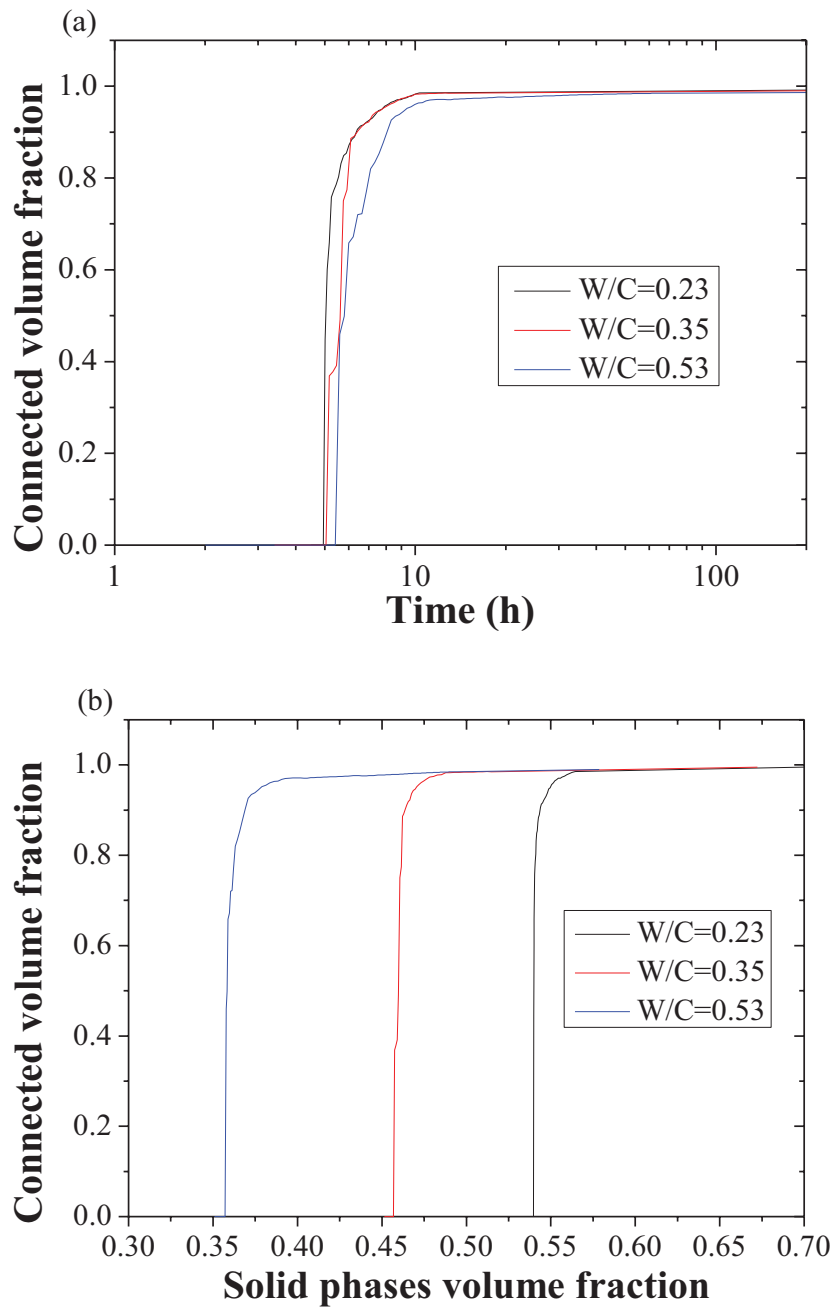

Figure 9. Development of solid phases modeled by CEMHYD3D (a) connected solid phases at different time (b) the volume fraction of connected solid phases as a function of all solid phases. appearance of solids percolation threshold for the cement pastes with a lower W/C, were reported by Garboczi and Bentz (2001) and Sun, Ye, and Shah (2005).

\subsubsection{Capillary pores de-percolation}

The capillary porosity and connectivity of pores evolution with time are simulated by CEMHYD3D, as shown in Figure 10. Initially, the porosity is 1 and capillary pores are entirely connected. With the development of hydration time, hydration products can precipitate and grow in free pore space, resulting in parts of capillary pores becoming isolated and connected porosity rapidly decreasing. Figure 10(a) presents that W/C also has a significant influence on de-percolation of capillary pores. An earlier first disconnection of capillary pores is reached for lower W/C. As the W/C decreases, the initial porosity decreases as well, and less hydration time
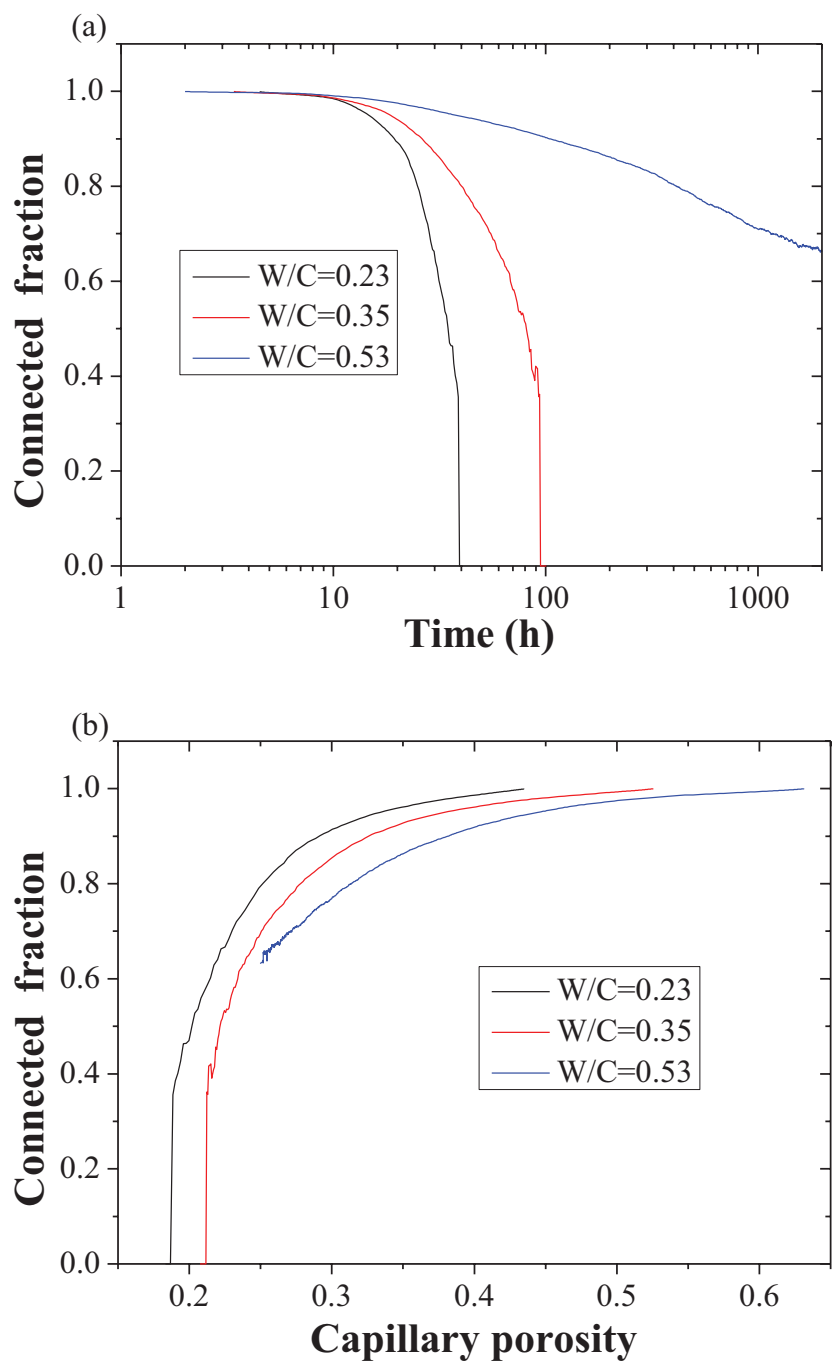

Figure 10. Development of capillary pores modeled by CEMHYD3D: (a) connected capillary pores at different time; (b) the volume fraction of connected capillary pores as a function of all capillary pores. 
(or products) is required to close off the water-filled pores. The relationship between capillary pores and connected capillary pores fraction are plotted in Figure 10(b). For all W/C cement pastes, the volume fraction of connected capillary pores steeply reduces with a drop in the capillary porosity due to hydration proceeding. It is noted from Figure 10(b) that the low W/C cement paste rapidly approach de-percolation threshold (about $0.18-0.22$ porosity), while paste with W/C of 0.53 cannot reach de-percolation threshold during the time period of experiment. According to Powers' model, cement paste with $\mathrm{W} / \mathrm{C}=0.53$ has a final capillary porosity of 0.2 at complete hydration. This implies that paste with W/C of 0.53 may be depercolated with several years of hydration.

\section{CONCLUSIONS}

Based on the above experimental and simulated results, the following conclusions can be drawn:

(a) The 3D numerical model of cement paste generated by CEMHYD3D is used to investigate the evolution of $3 D$ microstructure.

(b) The simulated mass of $\mathrm{CH}$ and $\mathrm{C}-\mathrm{S}-\mathrm{H}$ are in good agreement with the measured results. The maximum errors are 36.76 and $32.9 \%$, respectively.

\section{ACKNOWLEDGMENTS}

The authors gratefully acknowledge the financial support from 973 Program (2009CB623200), National natural science foundation of China (51138002, 51178106), Ph.D. Programs Foundation of Ministry of Education of China (No. 20100092110029), Postgraduates Research Innovation in University of Jiangsu Province (CX10B-064Z) and Scientific Research Foundation of Graduate School of Southeast University (YBJJ1111).

\section{REFERENCES}

Bentz, D. P. (2005). CEMHYD3D: A threedimensional cement hydration and microstructure development modeling package. Version 3.0. U.S. Department of Commerce.

Bentz, D. P. (2006). Capillary porosity depercolation/ repercolation in hydrating cement pastes via low-temperature calorimetry measurements and CEMHYD3D modeling. Journal of the American Ceramic Society, 89(8), 2606-2611.

Garboczi, E. J., \& Bentz, D. P. (2001). The effect of statistical fluctuation, finite size error, and digital resolution on the phase percolation and transport properties of the NIST cement hydration model. Cement and Concrete Research, 31(10), 1501-1514.

Liu, Z., Zhang, Y., Jiang, Q., Sun, G., \& Zhang, W. (2011). In situ continuously monitoring the early age microstructure evolution of cementitious materials using ultrasonic measurement. Construction and Building Materials, 25(10), 3998-4005.

Liu, Z., Zhang, Y., Sun, G., \& Jiang, Q. (2012). Observation of microstructure formation process of cement paste using non-destructive methods. Magazine of Concrete Research, 64(11), 957-965.

Scrivener, K. L., Fullmann, A., Gallucci, E., Walenta, G., \& Bermejo, E. (2004). Quantitative study of Portland cement hydration by X-ray diffraction/ Rietveld analysis and independent methods. Cement and Concrete Research, 34(9), 1541-1547.

Sun, Z. H., Ye, G., \& Shah, S. P. (2005). Microstructure and early-age properties of Portland cement paste - Effects of connectivity of solid phases. ACI Materials Journal, 102(2), 122-129.

Venkiteela, G., \& Sun, Z. H. (2010). In situ observation of cement particle growth during setting. Cement and Concrete Composites, 32(3), 211-218.

Xiao, L., \& Li, Z. (2009). New understanding of cement hydration mechanism through electrical resistivity measurement and microstructure investigations. Journal of Materials in Civil Engineering, 21(8), 368-373.

YImen, R., Jaglid, U., Steenari, B. M., \& Panas, I. (2009). Early hydration and setting of Portland cement monitored by IR, SEM and Vicat techniques. Cement and Concrete Research, 39(5), 433-439.

Zhang, Y., Zhang, W., She, W., Ma, L., \& Zhu, W. (2012). Ultrasound monitoring of setting and hardening process of ultra-high performance cementitious materials. NDT \& $E$ International, 47, 177-184. 